\title{
PENGGUNAAN APLIKASI GEOGEBRA SEBAGAI MEDIA PEMBELAJARAN MATEMATIKA SMK
}

\author{
Taufik Hidayat \\ SMK Negeri 6 Sijunjung \\ email: taufikhidayatk6@gmail.com
}

\begin{abstract}
The rapid development of technology helps humans in carrying out various things, especially in the world in using an application as a learning medium. In order for students to easily understand the mathematical concepts taught by the teacher at the vocational level, teachers also help them to support each teacher's activities starting from planning, implementing and evaluating learning. One of the applications used in the teaching of vocational high schools is Geogebra, Geogebra. The first trick was developed by Markus Hohenwarter in 2001. Geogebra is an application that can help teachers in learning mathematics, especially Geometrid and Algebra. In its use, Geogebra as a Learning Media can be used as a media demonstration, construction or drawing tools, exploration tools and confirmation tools. Applications can also be downloaded freely at ww.geogebra.com. Geogebra can also be installed on a personal computer so that teachers can use it anytime and anywhere to support mathematics learning. With the hope that the Geogebra application can help teachers convey mathematical concepts
\end{abstract}

Keywords: Geogebra, Learning Media, Use of Geogebra, SMK Mathematics

\begin{abstract}
ABSTRAK
Perkembangan teknologi yang pesat membantu manusia dalam melaksanakan berbagai hal, khususnya dalam dunia dalam penggunaaan sebuah aplikasi sebagai media pembelajaran. Agar siswa dapat dengan mudah memahami konsep matematika yang diajakan guru pada tingkat SMK, Selain itu bagi guru juga membantunya dalam menunjang setiap aktivitas guru mulai dari merencanakan, pelaksanaan dan Evaluasi pembelajaran. Salah satu Aplikasi yang digunakan dalam pembelakjaran SMK adalah Geogebra, Geogebra Pertama akali dikembangkan oleh Markus Hohenwarter Pada tahun 2001.Geogebra merupakan Aplikasi yang dapat membantu guru dalam pembelajaran matematika khususnya Geometrid dan Aljabar. Dalam pemanfaatannya Geogebra sebagai Media Pembelajaran dapat dgunakan sebagai Media demonstrasi, Alat bantu Konsruksiatau Gambar, Alat bantu Ekslprorasi dan alat Konfirmasi. Aplikasi juga dapat didownload secara bebas di ww.geogebra.com. Geogebra juga dapat diinstal di komputer pribadi sehingga dapat digunakan guru kapan dan dimana saja untuk menjunjang pembelajaran matematika. Dengan harapan aplikasi Geogebra dapat membantu guru menyampaikan konsep-konsep matematika

Kata Kunci: Geogebra, Media Pembelajaran, Penggunaan Geogebra, Matematika SMK
\end{abstract}




\section{PENDAHULUAN}

Matematika merupakan mata pelajaran yang penting perlu dikuasai oleh peserta didik, dimana banyak masalah dalam kehidupan sehari-hari diselesaikan dengan konsep matematika. Beberapa contoh maslah tersebut misalnya menentukan luas suatu lahan, menentukan laba maksimum pada suatu barang, menentukan luas dan volume suatu bangun dan masih banyak yang lainya.

Mempelajari matematika bertujuan agar peserta didik dapat berpikir secara logis, kritis, kreatif dan dapat berkerjasama (Depdiknas 2006:416). Hal itu sesuai dengan empat kompetensi yang harus dimiliki siswa di abad 21 yang disebut 4C, yaitu Critical Thinking and Problem Solving (berpikir kritis dan menyelesaikan masalah), Creativity (kreativitas), Communication Skills (kemampuan berkomunikasi), dan Ability to Work Collaboratively (kemampuan untuk bekerja sama).

Untuk menunjang tercapainya tujuan pembelajaran tersebut diharapkan guru dapat melibatkan siswa aktif dalam proses pembelajaran. Sehingga pembelajaran tidak berpusat kepada guru, tetapi berpusat pada siswa. Salah cara agar pembelajaran terpusat pada siswa dapat dirangsang apabila guru menyediakan bahan ajar, lembar kerja serta media sebagai sarana untuk menarik minat peserta didik belajar dan terlibat aktif selama pembelajaran.

Penggunaan media dalam pembelajaran matematika diharapkan dapat membantu peserta didik memahami konsep matematika yang dipelajari. Jika konsep mudah dipahami maka akan berpengaruh psikologis yang positif terhadap motivasi belajar peserta didik. Selain itu dengan media juga membantu memperlancar interaksi antara guru dan peserta didik sehingga lebih efektif dan efisien.

Pada abad 21 saat ini kecanggihan teknologi sudah sangat pesat peningkatnya jika dibandingkan pada beberapa puluh tahun yang lalu. Sehingga jika tidak dimanfaatkan maka akan menjadi sesuatu yang sia-sia. Salah satu kecanggihan teknologi hari ini terbukti dengan ada berbagai macam kegiatan mulai dari mall, perkantor sampai kesekolah telah banyak menggunakan computer. Penggunaaan computer ini tidak hanya membantu pekerjaan didunia kerja namu juga dapat digunakan sebagai media pembelajaran.

Penggunaan computer sebagai media pembelajaran pada umumnya memanfaatkan beragam aplikasi yang dapat di install di computer. Salah satu aplikasi akhir banyak digunakan adalah aplikasi GeoGebra. Yoel (2018) menyatakan GeoGebra sangat berperan penting dalam membantu guru matematika untuk mevisualisasikan materi matematika tidak hanya tampilan 2D saja yang disajikan, pada GeoGebra Juga dapat menampilkan 3D sehingga pembelejaran pun menjadi sangat menyenangkan.

Namun pada kenyataan masih banyak guru matematika yang lebih memilih melakukan pembelajaran dengan menggunakan media seadanya saja dan tidak banyak menggunakan teknologi sebagai penunjang. Pembelajaran yang dilaksanakan guru tersebut Diwali dengan menjelaskan teori dengan media seadanya, memberikan rumus, contoh soal kemudian memberikan soal yang akan diselesaikan oleh peserta didik.

Dan pada saat menggambarkan grafik visualisasi guru hanya menggambar dengan menggunakan penggaris, spidol dan alat seadanya, Sehingga hasil visualisasi dari sketsa atau gambar matematika kadang kurang sesuai dengan 
gambar yang benarnya. Ketika ditanya tentang apliksi tersebut, banyak guru yang sudah mengenal aplikasi tetapi belum tahu bagaimana cara mengaplikasikannya pada pembelajaran di kelas.

Berdasarkan paparan tersebut Penulis ingin menjelaskan bagaimana memanfaatkan Aplikasi Geogebra dalam Pembelajaran Matematika SMK, Baik sebagai Alat Demonstrasi, Alat bantu konstuksi, alat bantu Eksplorasi dan Alat konfirmasi serta Kompetensi dasar apa saja yang dapat menggunakan Aplikasi Geogebra. Sehingga dapat menunjang aktivitas guru dalam mengajarkan konsep Matematika kepada peserta didik.

Menurut Hohenwarter \& Fuchs (2004) GeoGebra sangat bermanfaat sebagai media pembelajaran matematika dengan beragam aktivitas sebagai berikut.

1. Sebagai media demonstrasi dan visualisasi

Dalam hal ini, dalam pembelajaran yang bersifat tradisional, guru memanfaatkan GeoGebra untuk mendemonstrasikan dan memvisualisasikan konsep-konsep matematika tertentu.

2. Sebagai alat bantu konstruksi

Dalam hal ini GeoGebra digunakan untuk memvisualisasikan konstruksi konsep matematika tertentu, misalnya mengkonstruksi lingkaran dalam maupun lingkaran luar segitiga, atau garis singgung.

3. Sebagai alat bantu proses penemuan

Dalam hal ini GeoGebra digunakan sebagai alat bantu bagi siswa untuk menemukan suatu konsep matematis, misalnya tempat kedudukan titik-titik atau karakteristik grafik parabola

4. Sebagai Konfirmasi

Dalam ini Peserta didik dan Guru dapat memeriksa jawaban dari permasalahan, misalnya mencek jawaban, menetukan Akar-akar persamaan Kuadrat, Menentukan penyelesaian Persamaan dan pertidaksamaan

Pada Aplikasi GeoGebra terdapat beberapa tampilan, yaitu : (1) Мепи, (2)Toolbar, (3) kolom Input. Pada tampilan Menu terdapat beberapa pilihan yaitu, File, Edit, View, Option, Tools, Windows, Help. Seperti gambar berikut

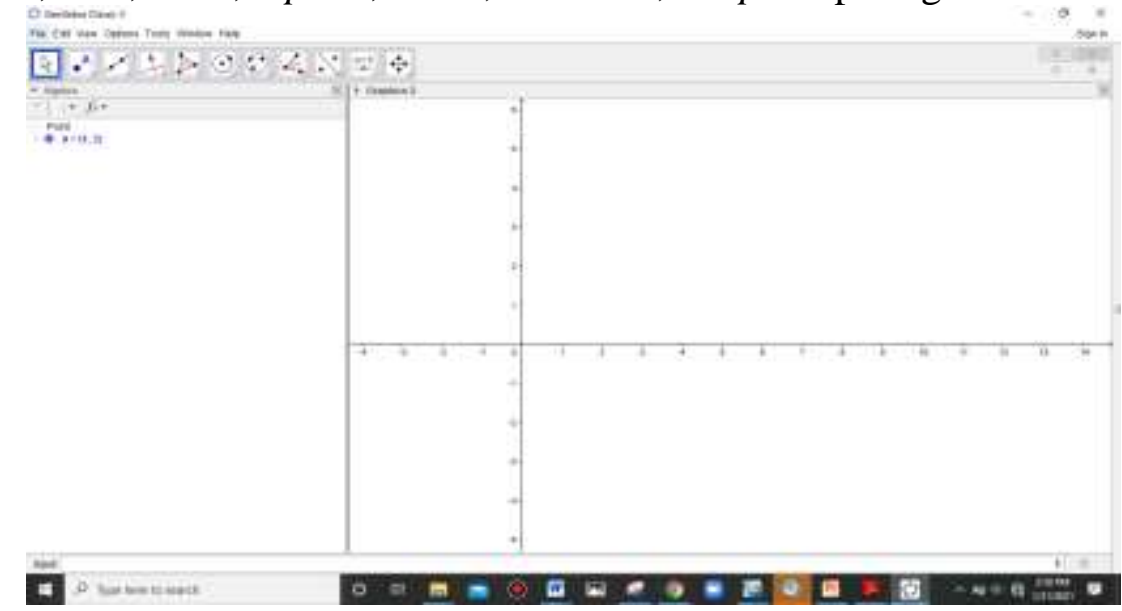

Pada File terdapat beberpa pilihan: New Windows yang digunakan membuka tab atau jendela baru, New untuk membuka lembaran tanpa menambah tab, Open untuk membuka file yang sudah dibuat dan disimpan, Open recent adalah untuk memilih file yang pernah kita buka sebelumya. Save digunakan untuk menyimpan projek yang telah dibuat, sedangkan save as menyimpan file dengan 
nama baru tanpa mengubah file asli. Share digunakan ke akun Geogebra. Eksport digunakan untuk menyimpan file dalam bentuk ekstensi lainya Picture ( $P N G$, JPEG), Animated GIF, dll.

Pada menu Edit, terdapat beberapa pilihan undo ( membatalkan apa yang telah dilakukan ), redo ( mengembalikan lagi), dll, digunakan untuk mengedit objek yang telah diinput. misalnya menyembunyikan objek maupun labelnya, bahkan dapat juga menghapus objek yang dipilih. Pada menu View, terdapat banyak pilihan yang akan ditampilkan pada jendela yaitu : Algebra, Spreadsheet, CAS, Grafics 2D dan 3D, Condtruktion protocol, Probability Calculator, dll. Pada menu Option terdapat pilihan Labeling untuk setingan pelabelan objek, Font Size untuk megubah ukuran huruf, Languange menyeting bahasa yang akan digunakan, tersedia 70 bahasa termasuk bahasa Indonesia. Menu Tools digunakan menyeting apa saja yang ikon tools yang akan ditampilkan pada tools bar seperti pada gambar berikut:

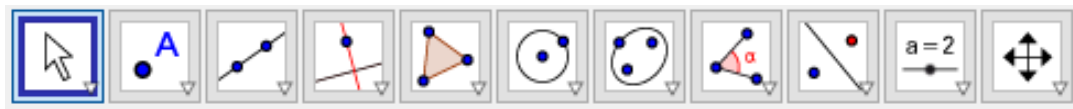

Sementara Menu Windows adalah untuk menambah jendela baru. sedangkan Help adalah menu terakhir untuk membantu pengguna dalam menggunakan aplikasi baik tutorial maupun manual dan harus diakses secara online.

\section{METODOLOGI}

Contoh Penerapan Geogebra Pada Materi Matematika SMK

1. Membuat Persamaan Garis Lurus

Contoh :

Tentukan persamaan garis yang melalui titik $(2,3)$ dan $(-1,0)$ !

Penyelesaian dengan GeoGebra

pilih pada point pada toolbar, klik posisi kedua titikA(2,3) dan $\mathrm{B}(-1,0)$

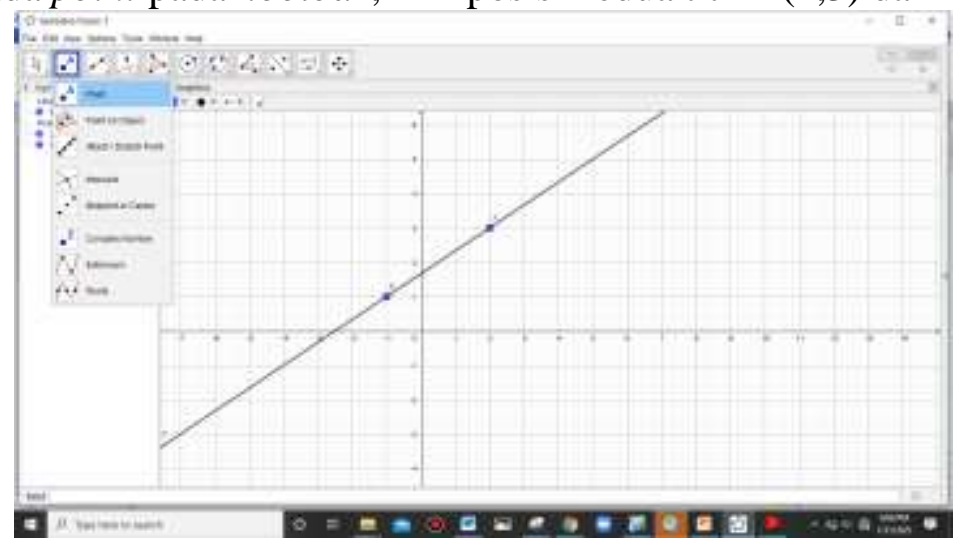

2. Menentukan Persamaan Garis Singgung Lingkaran yang ditarik dari titik diluar Lingkaran

Contoh :

Menentukan persamaan garis Singgung pada lingkaran $x^{2}+y^{2}-8 x-4 y+$ $16=0$ yang ditarik titik $(0,2)$

a. Gambar lingkaran dengan cara ketik “ $\mathrm{x}^{\wedge} 2+\mathrm{y}^{\wedge} 2-8 \mathrm{x}-4 \mathrm{y}+26=0$ pada kolom Input, tekan Enter

b. Gambar titik $(0,2)$ dengan cara ketik $(0,2)$ pada kolom input, tekan Enter 


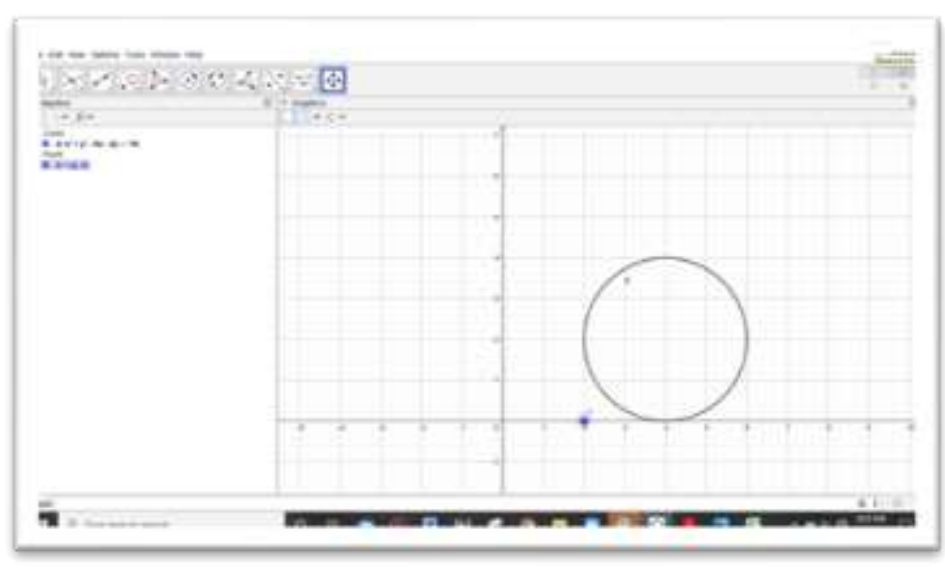

c. Menggunakan

tool polar

or

diameter

line

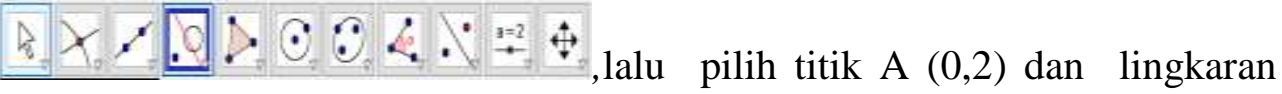
sehingga didapat garis polar
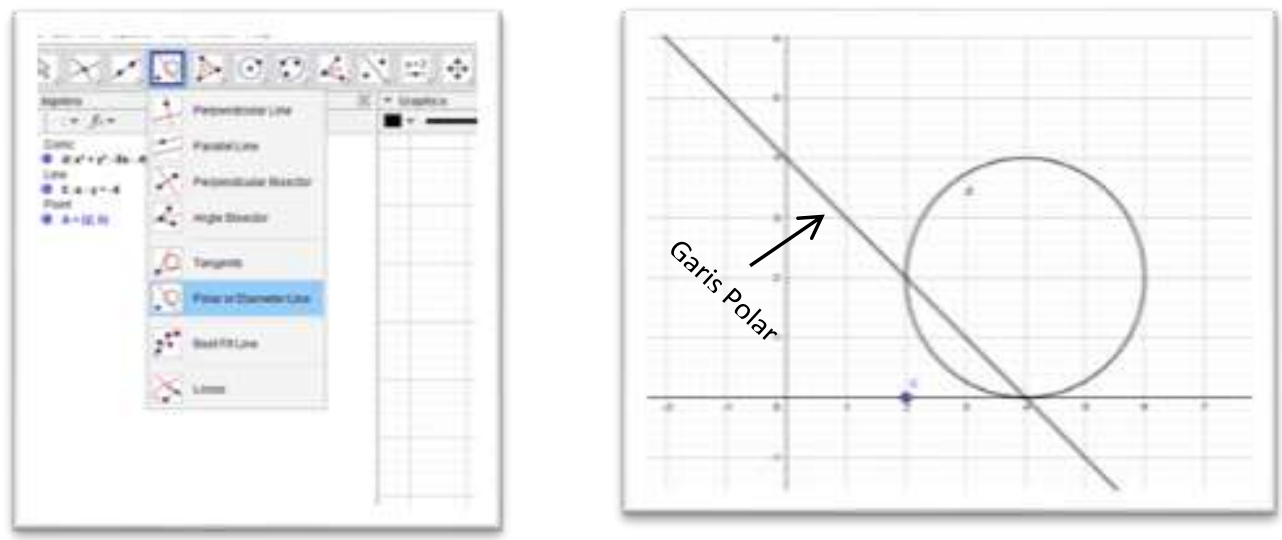

d. Tentukan titik potong garis polar dengan lingkaran dengan menggunakan tool intersect sehingga didapat titik $\mathrm{B}$ dan $\mathrm{C}$
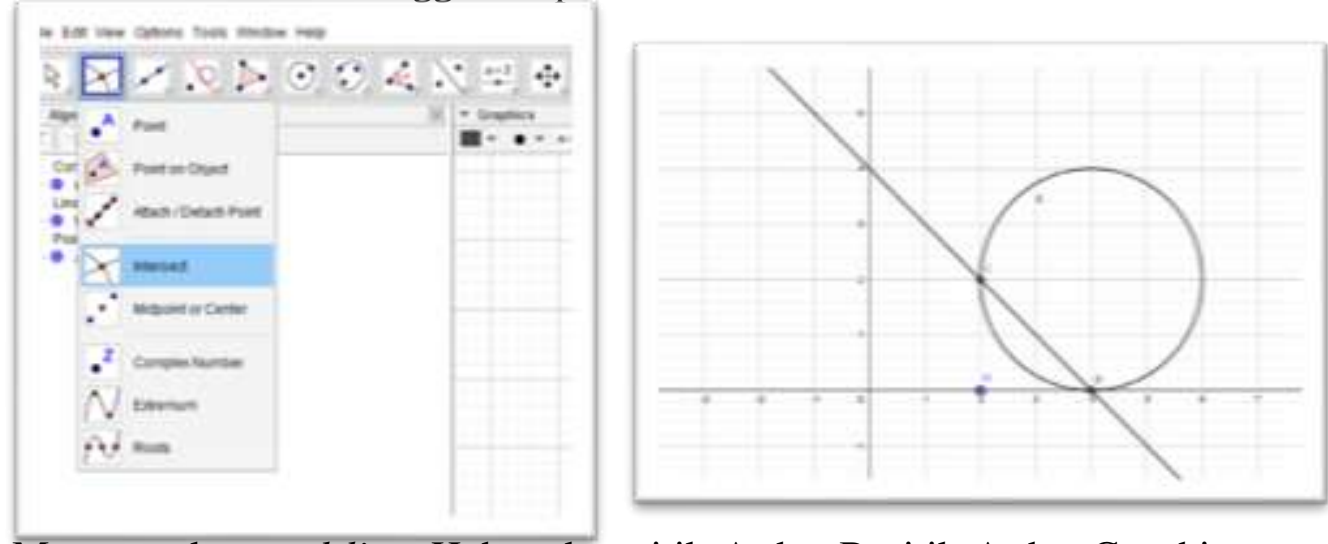

e. Menggunakan tool line, Hubungkan titik A dan $\mathrm{B}$, titik A dan $\mathrm{C}$, sehingga didapatkan Dua Garis Singgung $x=2$ dan $y=0$, dan persamaannya dapat dilihat di Jendela Aljabarnya 


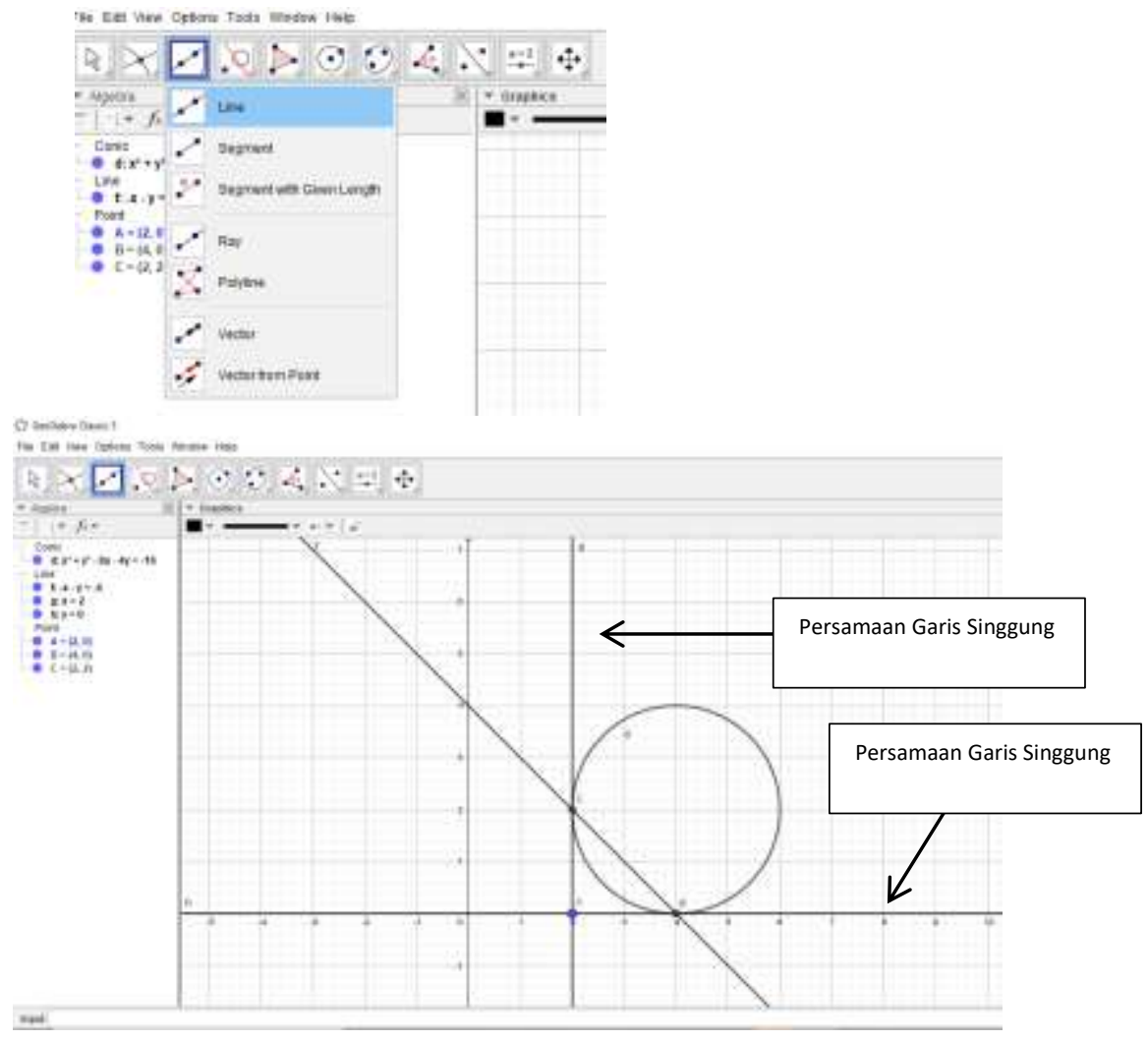

\section{Menentukan Refleksi Bangun Datar terhadap garis}

Contoh Soal :

Tentukan hasil refleksi Segitiga ABC dimana titik $A(4,4), B(8,2)$ dan $C(3,1)$

Terhadap garis $y=3 x$ !

Dengan Geogebra Jawaban Peserta didik dapat dicek. dengan langkah sebagai berikut :

a. Buatlah titik $A(4,4), B(8,2)$ dan $C(3,1)$ mengggunakan tool point $\bullet^{\mathrm{A}}$ Sehingga didapat gambar

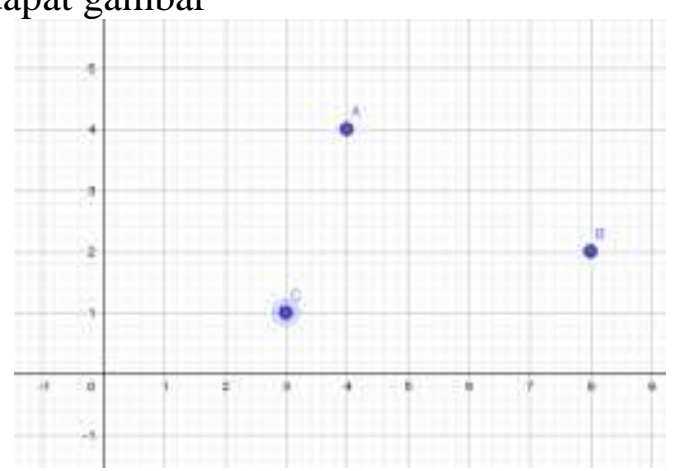

b. Buatlah segitiga $\mathrm{ABC}$ dengan menghubungkan ketiga titik $\mathrm{A}, \mathrm{B}$ dan $\mathrm{C}$ dengan tool polygon , dimulai dengan mengklik A-B-C-A . 


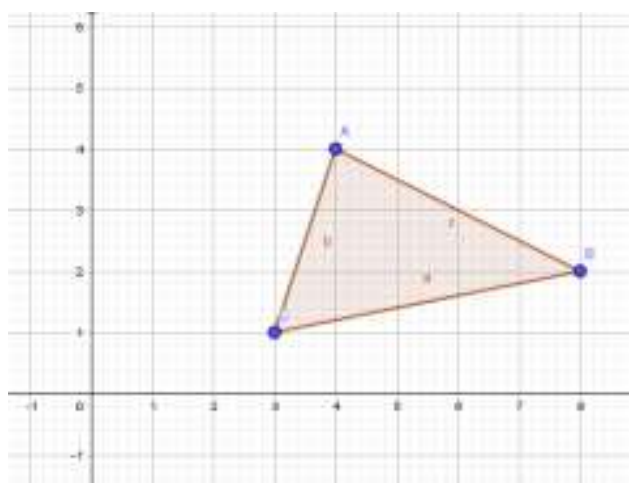

c. Buatlah garis $y=3 x$ dengan mengetik dikolom input $y=3 x$ lalu tekan enter

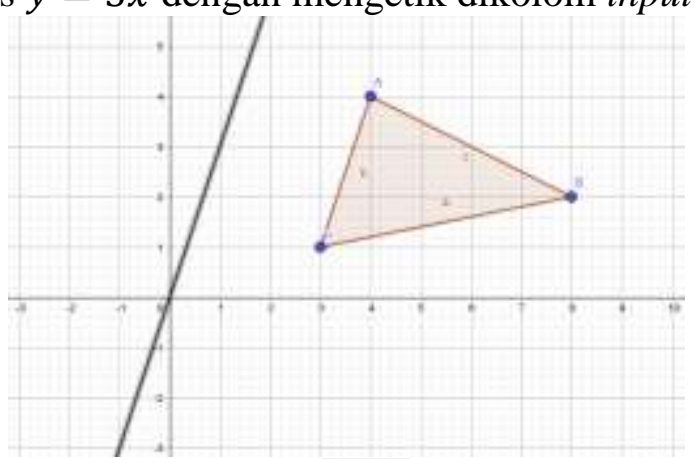

d. Pilih tol Reflect about Line

untuk mencerminkan segitiga $\mathrm{ABC}$, Dengan cara Klik titik A kemudian garis $y=3 x$ sehingga muncul titik A'. Klik titik B kemudian klik garis $y=3 x$ sehingga muncul titik B'. Begitu juga dengan titik $\mathrm{C}$ akan muncul titik $\mathrm{C}$ '.

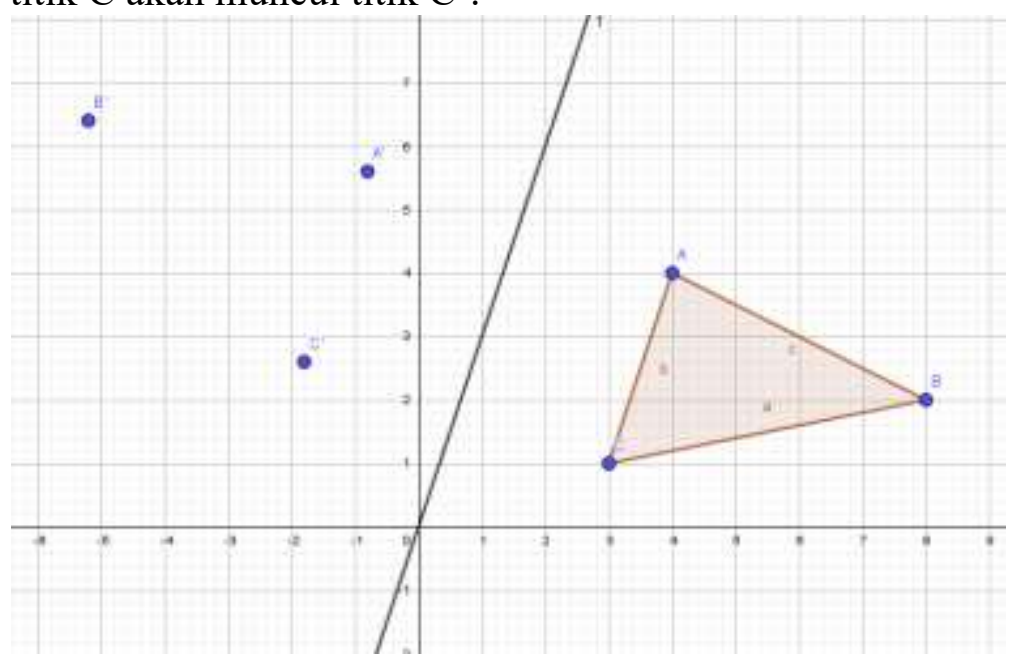

e. Buatlah Segitiga dengan menggunakan tool polygon sehingga di peroleh segitiga hasil refleksi sebagai berikut 


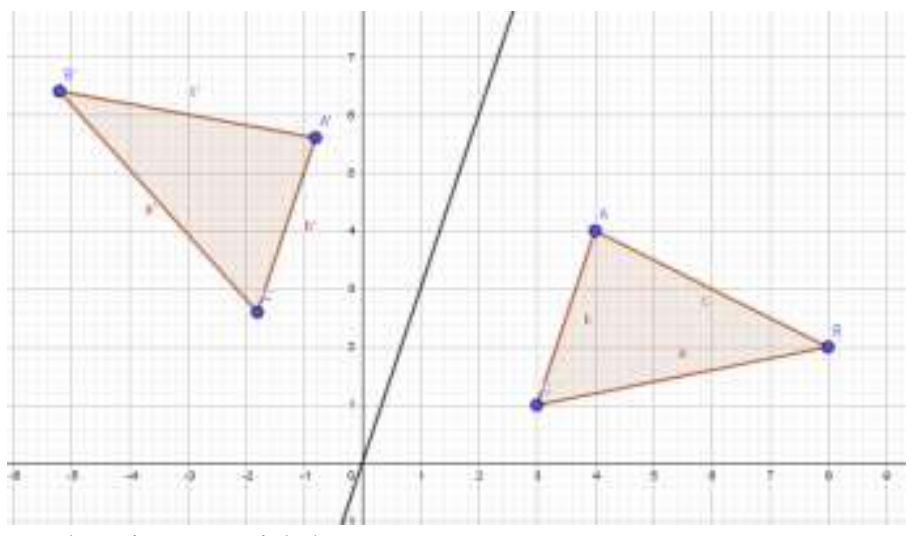

4. Menentukan Penyelesaian Pertidaksamaan

Contoh :

Tentukan himpunan penyelesaian dari $\frac{(2 x-3)}{5}<\frac{12+x}{2}$.

Dengan GeoGebra Penyelesianya dapat di cek dengan langkah sebagai berikut

1. Memilih menu View lalu pilih submenu $C A S$. Seperti pada gambar. Lalu ketikan " $((2 \mathrm{x}-3) / 5)<((12+\mathrm{x}) / 2)$ lalu tekan Enter
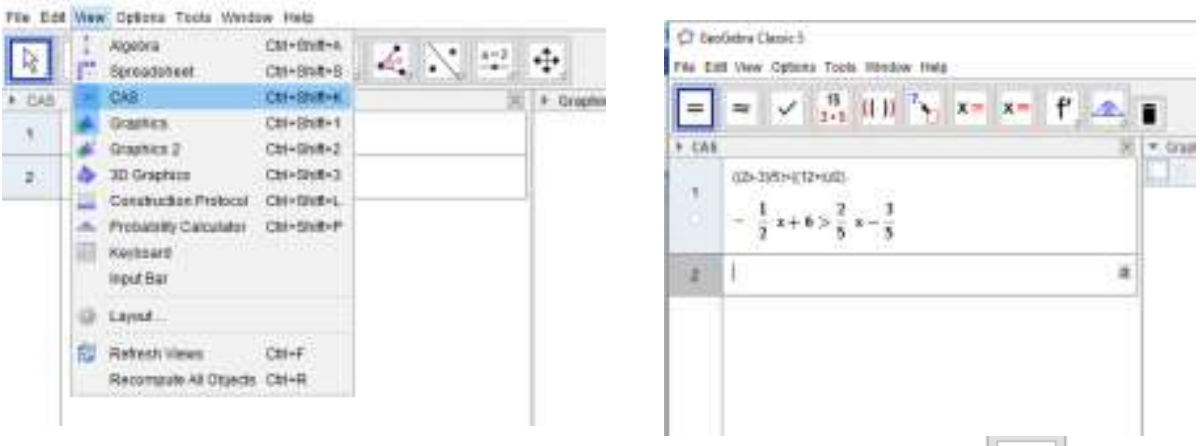

2. Selanjutnya pilih menu toolbar pada CAS yaitu solve $\stackrel{\mathrm{x}=}{=}$ sehingga di hasilkan penyelesaianya seperti gambar berikut

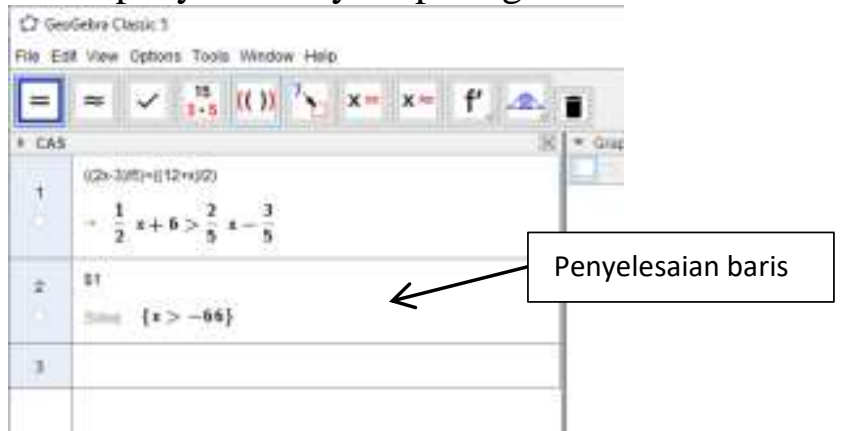

5. Menentukan Akar-akar Persamaan Kuadrat

Contoh Soal :

Himpunan penyelesaian dari persamaan $5 x^{2}+4 x-12=0$ adalah ....

Dengan menggunakan GeoGebra berikut langkah-langkahnya

1. Ketik pada baris input pada CAS “ $5 x^{\wedge} 2+4 x-12=0$ ” lalu tekan Enter 


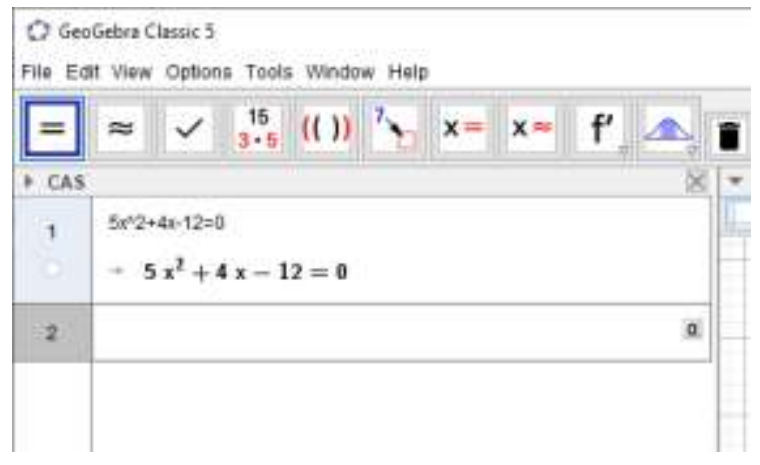

2. Untuk menyelesaikan Persamaan Kuadrat tersebut pilih solve $\mathrm{x}=$, Sehingga diperoleh Penyelesaiannya pada baris kedua. Dimana $\{x=$ $\left.-2, x=\frac{6}{5}\right\}$ seperti gambar berikut

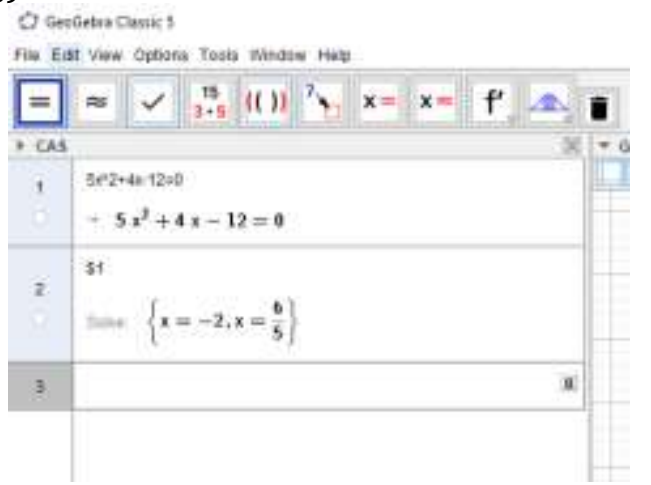

GeoGebra mempunyai fitur yang sangat lengkap sehingga mampu menggambar Grafik, Objek matematika Secara Tepat dan akurat, Versi terbaru GeoGebra Juga dapat menampilkan grafik Dimensi Tiga, CAS dan lain-lain. Selain itu Geogebra Juga dilengkapi versi bahasa lebih dari 60 bahasa, salah satunya Bahasa Indonesia.

Perlu disadari bahwa tidak ada media yang paling baik dan paling tepat untuk semua materi matematika, begitu juga dengan Aplikasi Geogebra, untuk menambah efektifitas media juga perlu dikombinasikan dengan media yang lain misalnya LKPD, Power Point, dan lain-lain.

\section{HASIL PENELITIAN}

Retno (2014) melakukan penelitian mengenai model pembelajaran tipe STAD berbantuan Geogebra penelitian berbentuk eksperimen yang terdiri dari 3 kelas yakni dua kelas eksperimen dan satu kelas control menunjukan hasil penelitian bahwa terdapat perbedaan kemampuan penalaran matematis siswa yang pembelajarannya menggunakan model kooperatif tipe STAD berbantuan software Geogebra dibandingkan dengan siswa yang pembelajarannya menggunakan model pembelajaran kooperatif tipe STAD tanpa berbantuan software Geogebra.[6] Nopiyanti (2012) dalam penelitianya mengenai pengembangan perangkat pembelajaran berbantuan geogebra pada materi geometri menunjukan bahwa perangkat yang dibuat memberikan dampak terhadap meningkatnya keterlibatan siswa dalam pembelajaran terlihat dari interaksi siswa dengan siswa dan siswa dengan guru serta rasa tanggung jawab siswa terhadap pembelajaran yang sedang dilaksanakan. 


\section{KESIMPULAN DAN SARAN}

Berdasarkan Pembahasan dapat disimpulkan bahwa Aplikasi GeoGebra dapat menunjang pembelajaran peserta didik di Sekolah. Perkembangan yang pesat saat ini perlu dimanfaatkan semaksimal mungkin, salah satu diantaranya memanfaatkan Aplikasi Geogebra sebagai Media Pembelajaran Matematika. Hal ini bertujuan untuk membantu Peserta didik Untuk memahami konsep matematika.

Geogebra dapat dimanfaatkan sebagai Media Pembelajaran dengan beberapa kegiatan sebagai Alat Demonstrasi dan visualisasi, Sebagai alat konstruksi bagaimana menggambar Garis Singgung Lingkaran, Membuat Jaring Limas, Melukis segitiga dengan Lingkaran luar, Sebagai Alat Konfirmasi.

Dalam Pemanfaatan Aplikasi Geogebra perlu disadari tidak ada aplikasi yang paling baik dan paling tepat. Namun demikian dengan menguasai Aplikasi ini dapat dimanfaatkan untuk mempermudah penguasaaan konsep matematika. Untuk mencapai efektitas juga dapat dikombinasikan dengan media pembelajaran yang lain seperti Power point, Sway, LKPD dan lain-lain.

\section{DAFTAR PUSTAKA}

Arirf rahman, S Christine S.T. 2007. Media Pendidikan. Jakarta : PT Raja Grafindo Persada.

Asngari,Dian Ramadhoni. Penggunaan GeoGebra dalam Pembelajaran Geometri. 2015. Yogyakarta : Seminar Nasional Matematika dan Pendidikan Matematika UNY 2015.

Iswanto, Yoel.2018. Cara Mudah Menguasai GeoGebra Sebagai Media Pembelajaran Matematika I. Banjar Masin: Barito Style.

B.Uno, Hamzah. 2007. Profesi Kependidikan Problematika, Solusi, dan Reformasi Pendidikan di Indonesia. Jakarta : Bumi Aksara.

Dian Romadhoni Asngari. 2010. Penggunaan Geogebra dalam Pembelajaran Geometri. Lampung: FKIP Universitas Lampung. ISBN. 978-602-73403$0-5$

Hohenwarter, M. \& Fuchs, K. (2004). Combination of Dynamic Geometry, Algebra, and Calculus in the Software System Geogebra.[Online] Tersedia; http://archive.geogebra.org/static/publications/pecs_2004 pp 3

Kasmina, dkk. 2018. Matematika untuk SMK/MAK Kelas X. Jakarta : Erlangga Kasmina, dkk. 2018. Matematika untuk SMK/MAK Kelas XI. Jakarta : Erlangga Kasmina, dkk. 2018. Matematika untuk SMK/MAK Kelas XII. Jakarta : Erlangga

Mahmud Ali. 2010. Membelajarkan Geometri dengan Program Geometri. Makalah Seminar Nasional Matematika dan Pendidikan Matematika UNY 2015

Nopiyanti Ni Luh Putu Ayu 2012 pengembangan perangkat pembelajaran geometri berbantuan geogebra dalam upaya meningkatkan keterlibatan dan prestasi belajar matematika siswa kelas vii. Tesis. Bali : Universitas Pendidikan Ganesha. pp 11 